РУДАКОВА Екатерина Константиновна - кандидат политических наук, доцент кафедры международных отношений и политологии, старший научный сотрудник Нижегородского государственного лингвистического университета им. Н.А. Добролюбова (603155, Россия, г. Нижний Новгород, ул. Минина, 31a, ekaterina-rudakowa@mail.ru)

\title{
ДЕМОГРАФИЧЕСКИЕ ПРОЦЕССЫ В ЕВРОПЕ: ДИНАМИКА И ПРИЧИНЫ ДЕПОПУЛЯЦИИ
}

\begin{abstract}
Аннотация. Статья посвящена рассмотрению причин депопуляционных процессов в Европе, выявленных в ходе анализа статистических данных демографических процессов на Европейском континенте. В зону анализа включены не только страны ЕС и еврозоны, а также страны, входящие в Европейскую ассоциацию свободной торговли. Статистическая информация была проанализирована по следующим показателям: рождаемость, иммиграция, эмиграция, аборты, репродуктивные установки молодежи. Проведенный анализ данных статистической службы Eurostat в период с 2007 по 2018 г. показал, что за редким исключением минимального прироста рождаемости все страны Европейского континента находятся в зоне серьезных процессов депопуляции, связанных с кризисом экономики, особенностями миграционной и семейной политики. Сделанные выводы могут быть использованы для корректировки демографической, миграционной и семейной политики России.
\end{abstract}

Ключевые слова: Европа, Евростат, депопуляция, демография, рождаемость, миграция, репродукция, аборты, безопасность

Д емографы свидетельствуют, что целые государства в мире сегодня встали на путь депопуляции; в некоторых странах это происходит сознательно - как переход к управляемой планируемой модели малодетной семьи, в других - по причинам военного или экономического характера. В западных странах фиксируется спад рождаемости, старение населения, рост числа абортов, снижение и угасание потребности в семье и детях, снижение фертильности. Это не просто цифры статистики, а отражение представлений общества о модели и ценностных основаниях будущего развития.

Очень часто в научной литературе тенденция депопуляции определяется как норма в терминах современного демографического перехода от традиционного к индустриальному и постиндустриальному обществу. Тем не менее явление депопуляции и, как следствие, трансформация традиционной модели общества и семьи неизбежно приводит к процессу сокращения рождаемости, малодетности, старения населения, что в длительной перспективе чревато потерей контроля государства над социальной системой и территорией. Процессы депопуляции известны с древности. Еще Полибий в своем труде «Всемирная история» описывает схожие процессы: «В наше время всю Элладу постигло бесплодие женщин и вообще убыль населения, так что города обезлюдели, пошли неурожаи, хотя мы не имели ни войн непрерывных, ни ужасов чумы». И далее, «дело в том, что люди испортились, стали тщеславны, любостяжательны и изнежены, не хотят заключать браки, а если и женятся, то не хотят вскармливать прижитых детей» [Полибий 2005].

По оптимистичному отчету статистиков ЕС от 1 января 2019 г., население Европы увеличилось на 1,1 млн чел. по сравнению с предыдущим, 2018 г. и составило 513,5 млн чел. Тем не менее в отчете не были представлены данные о том, что в большинстве стран Европейского континента ежегодно фиксируется стабильный спад рождаемости (за редким исключением стран, в которых наблюдается минимальный прирост при высоких показателях смертности и эмиграции). При этом отметим, что число мигрантов в странах Европейского 
континента в период с 2016 г. по настоящее время уже превысило 1,5 млн чел. Общей тенденцией для всех стран Европейского континента является сокращение численности коренного населения и его старение ${ }^{1}$.

В ходе анализа данных Евростата по показателю «рождаемость» (в период с 2008 по 2018 г.), было определено, что спад рождаемости фиксируется в Европе повсеместно. Эксперты связывают это с последствиями экономического кризиса 2009 г. При сравнении показателей рождаемости 2008 и 2018 гг. было выявлено, что практически во всех странах ЕС и ЕАСС за прошедшее десятилетие показатель рождаемости значительно снизился: в Испании - на 24\%, Италии $-22 \%$, Греции $-22 \%$, Финляндии $-18 \%$, Латвии $-19,3 \%$, Болгарии $-17 \%$, Португалии $-15 \%$, Ирландии $-14,5 \%$, Германии $-14 \%$, Хорватии $-11 \%$, Эстонии $-8,9 \%$, Нидерландах $-7,06 \%$, Франции $-7,3 \%$, Исландии $-7,2 \%$, Литве $-6,2 \%$, Великобритании - 5,3\%, Венгрии - 4,2\%, Румынии - 5,5\%, Дании $-4,0 \%$, Словении $-1,2 \%$, Чехии $-0,5 \%$. В сравнении с предкризисным 2008 г. в 2018 г. был отмечен рост рождаемости лишь в некоторых странах: в Мальте - на 18,03\%, Люксембурге - 14,5\%, Австрии - 12,1\%, Кипре - 8,7\%, Швеции $-7,8 \%$, Словакии $-5,8 \%$, Польше $-0,07 \%{ }^{2}$.

При сравнении показателей рождаемости 2017 и 2018 гг. был определен ряд стран, которые сохранили устойчивую ежегодную динамику спада рождаемости (см. табл.1). Это Латвия - в 2018 г. в стране родилось на 1514 тыс. чел. меньше, чем в предыдущем 2017 г. (сокращение рождаемости на 7,2\% в 2018 г. по сравнению с 2017 г.); Финляндия - 2744 (5,4\%); Испания - 20438 (5,2\%); Италия - 18404 (4,0\%); Польша - 13804 (3,4\%); Греция - 4205 (3,3\%); Словения - 656 $(3,2 \%)$; Великобритания - $23836(3,1 \%)$; Норвегия - $1513(2,6 \%)$; Австрия 2098 (2,3\%); Черногория - 192 (2,2\%); Литва - 547 (1,9\%); Франция - 10846 $(1,4 \%)$; Сербия - $919(1,4 \%)$; Венгрия - $1179(1,2 \%)$; Ирландия - $802(1,2 \%)$; Бельгия - 1371 (1,1\%); Нидерланды - $1311(0,7 \%)$; Словакия - $330(0,5 \%)^{3}$.

Самые низкие уровни рождаемости фиксируются в средиземноморских странах (Греция, Испания, Италия, Португалия). В Скандинавских странах, а также во Франции и Великобритании уровень рождаемости впервые находится на таком низком значении, но пока позволяет восполнить структуру населения за счет миграции. Страны Южной Европы и немецкоязычные страны демонстрируют чрезвычайно низкий уровень рождаемости, скорее всего по причине широко распространенной бездетности или семьи с одним ребенком. Немецкоязычные европейские страны, которые традиционно имели низкие показатели рождаемости, сегодня демонстрируют скромный рост до уровней коэффициента в 1,5-1,6 (в Германии в 2018 г. рождаемость выросла на 14\% по сравнению с 2007 г., в Австрии - на 14,9\%, в Швейцарии - на 17,2\%). Ситуация с бывшими социалистическими странами не так однозначна: здесь, согласно исследованиям, в разные годы наблюдаются всплески рождаемости, которые сменяются спадом, но данный рост не является тенденцией, и в ближайшей перспективе при сохранении современной политики модель низкой рождаемости может стать характерной и для этих стран. В странах - партнерах ЕС также фиксируется низкая рождаемость (Белоруссия, Россия, Украина, Грузия, Армения), исключением является Азербайджан и Турция, которые демонстрируют стабильный рост рождаемости. Для Турции

${ }^{1}$ Eurostat. Population by age group (2018). URL: https://ec.europa.eu/eurostat/tgm/table.do? tab $=$ table \&init $=1 \&$ plugin $=1 \&$ pcode $=$ tps $00010 \&$ language $=$ en

2 Eurostat. Live births and crude birth rate (2018). URL: https://ec.europa.eu/eurostat/tgm/ table.do?tab $=$ table \&init $=1 \&$ plugin $=1 \&$ pcode $=$ tps $00204 \&$ language $=$ en

3 Ibid. 
Таблица 1

\section{Динамика снижения рождаемости в странах ЕС и ЕАСС (по данным Евростата, тыс.чел.)}

\begin{tabular}{|c|c|c|c|}
\hline Страна & $\begin{array}{c}\text { Рождаемость, } \\
2017 \text { г. }\end{array}$ & $\begin{array}{c}\text { Рождаемость, } \\
2018 \text { г. }\end{array}$ & $\begin{array}{c}\text { Динамика снижения } \\
\text { рождаемости, } \\
\text { чел./ }\end{array}$ \\
\hline \multicolumn{4}{|c|}{ Страны ЕC } \\
\hline Венгрия & 94646 & 93467 & $1179 / 1,2$ \\
\hline Великобритания & 754754 & 730918 & $23836 / 3,1$ \\
\hline Франция & 770045 & 759199 & $10846 / 1,4$ \\
\hline Греция & 124501 & 120296 & $4205 / 3,3$ \\
\hline Испания & 391265 & 370827 & $20438 / 5,2$ \\
\hline Австрия & 87633 & 85535 & $2098 / 2,3$ \\
\hline Италия & 458151 & 439747 & $18404 / 4,0$ \\
\hline Нидерланды & 169836 & 168525 & $1311 / 0,7$ \\
\hline Болгария & 63955 & 62197 & $1758 / 2,7$ \\
\hline Чехия & 27316 & 26742 & $574 / 2,1$ \\
\hline Бельгия & 119690 & 118319 & $1371 / 1,1$ \\
\hline Финляндия & 50321 & 47577 & $2744 / 5,4$ \\
\hline Словакия & 57969 & 57639 & $330 / 0,5$ \\
\hline Латвия & 20828 & 19314 & $1514 / 7,2$ \\
\hline Литва & 28696 & 28149 & $547 / 1,9$ \\
\hline Польша & 401982 & 388178 & $13804 / 3,4$ \\
\hline Словения & 20241 & 19585 & $656 / 3,2$ \\
\hline Ирландия & 61824 & 61022 & $802 / 1,2$ \\
\hline \multicolumn{4}{|c|}{ Страны, не входящие в ЕС } \\
\hline Норвегия & 56633 & 55120 & $1513 / 2,6$ \\
\hline Сербия & 64894 & 63975 & $919 / 1,4$ \\
\hline Черногория & 7432 & 7264 & $192 / 2,2$ \\
\hline Северная Македония & 21754 & 21333 & $421 / 1,9$ \\
\hline Сан-Марино & 228 & 235 & $7 / 4,6$ \\
\hline
\end{tabular}

это связано в т.ч. и с тем, что она участвует в программе ЕС по принятию беженцев и перемещенных лиц ${ }^{1}$.

Европейские исследователи Жан Буссмар и Мишель Годэ демографическую ситуацию в Европе характеризуют как катастрофическую: «Поразительно, но никто не говорит о демографическом суициде Европы к 2050 г. Население Европы стареет и сокращается, а население Африки к 2050 г. вырастет на 1,3 миллиарда человек, при этом демографическое давление на Европу вырастет как никогда. Тем не менее Европа не говорит об этом демографическом шоке и едва ли готова к нему. Дефицит рождаемости не может быть скомпенсирован только

1 Ibid. 
за счет мигрантов, - если Европа хочет сохранить открытость миру, ей следует сейчас заняться подъемом рождаемости» [Boussemart, Godet 2018].

Действительно, в период с момента экономического кризиса 2009 г. по настоящее время общий коэффициент рождаемости в странах ЕС находится на крайне низком уровне и составляет 1,6 , не претерпевая значительных изменений год от года $(2012$ г. - 1,59; $2015-1,58)$. Критический порог в 1,3 не фиксируется в странах ЕС, однако Испания, Италия, Португалия, Кипр, Мальта в 2016 г. были очень близки к данному значению. Наблюдается тенденция снижения рождаемости до среднего уровня в 1,6 даже в странах, которые ранее имели показатель не менее 2,0 (Франция, Ирландия, Швеция, Великобритания, а также не входящие в ЕС Исландия и Норвегия), ни одно государство ЕС более не достигает такого уровня рождаемости (см. табл. 1).

Таблица 1

\section{Коэффициент рождаемости в странах ЕС (по данным Евростата, 2016 г. ${ }^{1}$ )}

\begin{tabular}{|l|l|l|l|}
\hline Испания & 1,34 & Словения & 1,58 \\
\hline Италия & 1,34 & Германия & 1,60 \\
\hline Португалия & 1,36 & Эстония & 1,60 \\
\hline Кипр & 1,37 & Чехия & 1,63 \\
\hline Мальта & 1,37 & Румыния & 1,64 \\
\hline Греция & 1,38 & Нидерланды & 1,66 \\
\hline Польша & 1,39 & Бельгия & 1,68 \\
\hline Люксембург & 1,41 & Литва & 1,69 \\
\hline Хорватия & 1,42 & Латвия & 1,74 \\
\hline Словакия & 1,48 & Дания & 1,79 \\
\hline Венгрия & 1,53 & Великобритания & 1,79 \\
\hline Австрия & 1,53 & Ирландия & 1,81 \\
\hline Болгария & 1,54 & Швеция & 1,85 \\
\hline Финляндия & 1,57 & Франция & 1,92 \\
\hline
\end{tabular}

Опросы европейской молодежи повсеместно демонстрируют угасание потребности индивида в семье и детях. Современное поколение европейцев сегодня имеет в два-три раза детей меньше, чем поколение их родителей. Так, страны Скандинавии исторически были первыми по показателям рождаемости. Сегодня здесь очевидна тенденция демографического спада, темпы естественного прироста сопоставимы с показателями смертности и миграционного прироста, число абортов сопоставимо с уровнем естественного прироста, наблюдается старение коренного населения и этническое замещение местного населения мигрантами. Показатели бездетности в Европе сегодня сопоставимы с первыми десятилетиями XX в., когда многие оставались бездетными по причине войн и экономической депрессии; тогда уровень бездетности достигал 17-25\%. Сегодня схожие показатели бездетности фиксируются в Северной Европе (15\%) и Западной Европе (18\%) в условиях мирного времени и при высоких показателях уровня жизни [Фролов 2017].

В то время как для работающей европейской молодежи все более привле-

\footnotetext{
1 Ibid.
} 
кательными становятся идеи малодетности и бездетности, анализ статистики показал, что с 2009 г. в Европе наблюдается рост многодетных семей - с тремя и более детьми. Как полагают эксперты Евростата, это явление связано с ростом рождаемости в семьях мигрантов из Пакистана, Афганистана, Бангладеша, Нигерии, для которых многодетность является традицией, а также залогом получения социального статуса и финансового стимулирования. Самый большой процент семей с тремя и более детьми фиксируется в Ирландии $(27 \%)$, Финляндии (20\%), Бельгии (19\%), Франции, Нидерландах, Великобритании (по 17\%). Заметим, что это страны, в которых наблюдается самый значительный миграционный прирост ${ }^{1}$ [Перассо 2015].

Среди причин того, почему европейская молодежь не спешит заводить семью и детей, на первом месте стоит экономическая и миграционная политика. В результате экономического кризиса 2009 г. немалая доля молодых европейцев «поколения миллениума» оказалась перед лицом безработицы. Доля безработных в странах ЕС в 2018 г. составила 16,1\%, самые большие показатели в Греции $-39,9 \%$, Испании - 34,3\%, Италии - 32,2\%, Хорватии - 23,7\%, Франции $20,8 \%$, Португалии - 20,3\%2. Рынки Европы переживают острую экономическую конкуренцию со стороны стран АТР. Экономическая статистика свидетельствует, что перспективы на рынке труда и политика «открытых границ» для мигрантов делают рождение детей дорогим удовольствием. Многие молодые граждане отмечают риски социальной нестабильности с ростом серьезных преступлений в будущем, что вызывает опасения у молодежи и сдерживает их желание завести детей. К тому же по законам многих европейских государств необходимо иметь подтвержденный социальный статус, собственное жилье или стабильную работу, которая позволит оплачивать ипотечный кредит, но для этого необходимо вначале получить образование и квалификацию. Таким образом, для многих молодых граждан Европы финансовая самостоятельность наступает не раньше 30-40 лет. Рост цен на жилье как результат миграционной политики также привел к тому, что сегодня оба родителя вынуждены работать, что не стимулирует расширение семьи [Skaug 2017].

Жители Европы также обеспокоены проблемой миграции. Они полагают, что финансовое стимулирование рождаемости должно касаться только коренного населения, иначе дети в будущем «останутся в меньшинстве среди враждебного окружения мигрантов». Опросы показывают, что многие молодые граждане Европы опасаются заводить детей по причине неуверенности в будущем из-за опасений, связанных с нелегальной миграцией: «Я очень хорошо понимаю молодежь, которая не рожает детей, рынок труда все более неопределенный, высокие цены на жилье пожирают экономику, делая детей дорогим удовольствием, можно было бы поддержать финансово молодых мам, но любой финансовый стимул будет стимулировать рост числа женщин-иммигрантов и их детей», - такие ответы получают социологи при исследовании отношения молодежи к мигрантам. По данным Евростата, в 2018 г. в странах ЕС было зафиксировано около 6,5 млн иммигрантов и около 4,6 млн эмигрантов 3 .

На фоне сложных экономических процессов происходит разрушение соци-

${ }^{1}$ Eurostat. Families with children in the EU (2018). URL: https://ec.europa.eu/eurostat/en/ web/products-eurostat-news/-/EDN-20170531-1

2 Eurostat. Unemployment rate by age (2018). Уровень безработицы в разбивке по возрасту (2018). URL: https://ec.europa.eu/eurostat/databrowser/view/tepsr_wc170/default/ table?lang=en

3 Eurostat. Total number of long-term immigrants arriving into the reporting country during the reference year (2018). URL: https://ec.europa.eu/eurostat/tgm/table.do?tab=table\&init=1\&plugi $\mathrm{n}=1 \&$ pcode $=$ tps $00176 \&$ language $=$ en 
альных институтов и маргинализация молодежи. Растет число тех, кто относится к так называемому проблемному поколению, которое не учится и не работает, остается исключенным из общественных процессов. По оценкам социологов, около 14 млн молодых людей в Европе в возрасте 15-24 лет принадлежат к группе «разочарованного» поколения (самые большие показатели в Греции $-27 \%$, Италии - 26\%, Болгарии - 24\%, Испании - 21\%). Они не зарегистрированы в социальных службах, многие не получили даже среднее образование и страдают зависимостями (14 млн наркозависимых), не способны найти работу. Растет доля психических заболеваний среди молодежи, в Великобритании этот показатель среди всех болезней достигает $28 \%$, что выводит их на 1-е место. Около 75\% страдающих психическими заболеваниями не стоят на учете и не получают лечение. По-прежнему высоким остается показатель по суицидам: в 2016 г. самые большие значения были зафиксированы в Литве - 28,27, Латвии 18,56, Словении - 18,09, Венгрии - 17,98, Бельгии - 17,11, Франции - 13,21 (из расчета на 100 тыс. чел.). Пока это тенденция лишь для незначительной части европейской молодежи, тем не менее это самая маргинальная и деморализованная ее часть ${ }^{1}$ [Пазына 2016].

Опросы показывают пессимизм молодых европейцев относительно собственного будущего и возможности получения стабильно оплачиваемой работы (1/3 респондентов). Для политических кругов Европы это проблема, ведь Арабская весна показала, что молодежь может стать детонатором протестов и социальных волнений. Именно поэтому европейские политики стали уделять молодежи большее внимание. Появился ряд программ, нацеленных на исправление сложившейся ситуации, - это «Европейская гарантия для молодежи», «Европейская инициатива по занятости», «Европейская стратегия по борьбе с распространением наркотиков» и др. [Социальное развитие... 2016].

Практически все страны Европы, за редким исключением (Польша, Албания - с коэффициентом 0,1 и 1,1 соответственно), имеют высокие показатели по абортам: в десятку стран с самым большим коэффициентом в 2017 г. вошли Болгария - 12,7, Венгрия - 10,2, Эстония $-11,0$, Исландия $-10,3$, Румыния - 10,1, Великобритания - 10,4, Дания - 9,3, Латвия $-7,3$, Испания, 7,0, Чехия - 6,5. В других странах Европы показатели незначительно меньше: Финляндия - 6,5, Словения, Италия - по 6,3, Словакия $-6,3$, Литва $-5,4$, Сербия $-5,3$, Португалия $-5,2$, Германия $-4,5$, Швейцария $-4,0$, Черногория $-3,5$, Хорватия $-2,1$.

На фоне ярко выраженной депопуляции европейские страны не демонстрируют борьбу за рождаемость. Анализ ситуации показал, что снижение числа абортов не является приоритетом демографической политики европейских стран. Напротив, при столь низких показателях рождаемости активно насаждается правозащитная проблематика в поддержку так называемого легального аборта, права на аборт. Данная проблематика активно продвигается в Европарламенте, ВО3, а также правозащитниками. Новой тенденцией стало внедрение в молодежной среде через СМИ установок, что «аборт не вреден», «аборт менее опасен, чем роды», смысловых конструктов «безопасный аборт», «право на аборт», «легальный аборт», «контрацептивный атлас», «мое тело мое дело». Понятие «репродуктивное здоровье» давно ассоциируется с безопасной контрацепцией и репродуктивными технологиями, а «репродуктивными» «женскими» правами признаны право на бездетность (childfree) и безопасный аборт [Устинкин, Рудакова, Эминов 2016].

${ }^{1}$ Eurostat. Death due to suicide (2018). URL: https://ec.europa.eu/eurostat/databrowser/view/ tps00122/default/table?lang=en 
Казалось бы, такая демографическая стратегия не в интересах европейских стран, однако, как показывает политика ведущих европейских государств, именно «право на аборт» сегодня является ведущей темой репродуктивной риторики Европы. Так, Франция в 2018 г. законодательно запретила пролайф-сайтам распространять информацию о негативных психологических и физиологических последствиях аборта. Аналогичной политики придерживается Великобритания и страны Скандинавии. Исключением является Венгрия, которая в 2017 г. законодательно запретила аборты не по медицинским показаниям (до этого времени страна долгое время занимала 1-е место в Европе по числу абортов). Данное решение в Западной Европе встретили критически, возможно, еще и потому, что Венгрия закрепила в Конституции положение, что брак - это союз между мужчиной и женщиной, а все остальное - гражданские союзы, поставив точку в спорах об однополых союзах и поддержав институт традиционной семьи.

Таким образом, проведенный анализ статистических данных показал, что Европа столкнулась с серьезными демографическими вызовами. Это выражается в стабильной динамике снижения рождаемости в целом и среди коренного населения, росте числа мигрантов и этническом замещении, высокой смертности. По причинам экономической нестабильности и рисков, связанных с нелегальной миграцией, происходит разрушение института семьи и социальной матрицы: для одних семья и дети становятся непосильным экономическим бременем в условиях безработицы, для других, не без воздействия антисемейной пропаганды, становятся лишь одной из жизненных альтернатив наравне с возможностями самореализации. Таким образом, можно сделать вывод, что политика Европы по полной легализации абортов и методам раннего полового воспитания и контрацепции не привела к должному результату. По всем странам Европы коэффициент абортов является высоким, в некоторых странах число абортов превышает число новорожденных. Полная легализация абортов привела к тому, что аборт стал массовым явлением, в т.ч. в отношении первой беременности, а запрет на распространение достоверной информации о негативных последствиях аборта ведет к увеличению их числа и снижению фертильности среди женщин детородного возраста.

\section{Список литературы}

Полибий. 2005. Всеобщая история в 3 томах. СПб: Наука. Т. 1. 496 с.

Пазына Е.О. 2016. Правовая охрана психического здоровья в Великобритании. - Мониторинг правоприменения. № 2(19). С. 77-81.

Перассо В. 2015. Почему в Европе растет рождаемость? 2015. Доступ: https:// www.bbc.com/russian/international/2015/08/150818_gch_world_fertility_rates (проверено 01.07.2020).

Социальное развитие Европы: проблемы и перспективы (под ред. М.В. Каргаловой). Доклады Института Европы РАН. 2016. Сборник № 326. М.: ИЕ РАН. $141 \mathrm{c.}$

Устинкин С.В., Рудакова Е.К., Эминов Д.С. 2016. Гендерные стратегии «мягкой силы» НПО как инструмент переформатирования культурного кода общества и государства в России. - Власть. № 1. С. 5-15.

Фролов Е. 2017. Почему европейцы все чаще предпочитают оставаться бездетными. - Демоскоп. № 711(712). 22.01.2017. Доступ: http://www.demoscope.ru/ weekly/2017/0711/gazeta04.php (проверено 01.07.2020)

Boussemart J., Godet M. 2018. Europe 2050: Demographic Suicide. 2018. URL: https://www.robert-schuman.eu/en/european-issues/0462-europe-2050-demographic-suicide (accessed 26.07.2020). 
Skaug C. 2017. Lavere fruktbarhet hos norske kvinner. - Fornuft Frihet. 03.03.2017. URL: https://www.document.no/2017/03/03/lavere-fruktbarhet-hos-norske-kvinner/ (проверено 01.07.2020).

RUDAKOVA Ekaterina Konstantinovna, Cand.Sci. (Pol.Sci.), Associate Professor, Senior Researcher of the Chair of International Relations and Political Science, Dobroljubov State Linguistics University of Nizhny Novgorod (31a Minina St, Nizhny Novgorod, Russia, 603155; ekaterina-rudakowa@mail.ru)

\title{
DEMOGRAPHIC PROCESSES IN EUROPE: DYNAMICS AND REASONS FOR DEPOPULATION
}

\begin{abstract}
The article is devoted to the consideration of the causes of depopulation processes in Europe identified during the analysis of statistical data on demographic processes on the European continent. The analysis area includes not only EU and Eurozone countries, but also countries that are members of the European Free Trade Association. Statistical information was analyzed according to the following indicators: fertility, immigration, emigration, abortion, reproductive attitudes of young people. The analysis of the data of the Eurostat in the period from 2007 to 2018 showed that with rare exceptions of a minimal increase in the birth rate, all the countries of the European continent are in the zone of serious depopulation processes associated with the economic crisis, features of migration and family policies. The findings can be used to adjust the demographic, migration and family policies in Russia.
\end{abstract}

Keywords: Europe, Eurostat, depopulation, demography, birth rate, migration, reproduction, abortion, safety 